Article

\title{
Kinetics of the Lattice Response to Hydrogen Absorption in Thin Pd and CoPd Films
}

\author{
Sudhansu Sekhar Das ${ }^{\circledR}$, Gregory Kopnov and Alexander Gerber * \\ Raymond and Beverly Sackler Faculty of Exact Sciences, School of Physics and Astronomy, Tel Aviv University, \\ Ramat Aviv, Tel Aviv 69978, Israel; sudhansu@tauex.tau.ac.il (S.S.D.); kopnov@tauex.tau.ac.il (G.K.) \\ * Correspondence: gerber@tauex.tau.ac.il
}

Received: 3 July 2020; Accepted: 5 August 2020; Published: 7 August 2020

check for updates

\begin{abstract}
Hydrogen can penetrate reversibly a number of metals, occupy the interstitial sites and cause large expansion of the crystal lattice. The question discussed here is whether the kinetics of the structural response matches hydrogen absorption. We show that thin Pd and CoPd films exposed to a relatively rich hydrogen atmosphere $\left(4 \% \mathrm{H}_{2}\right)$ inflate irreversibly, demonstrate the controllable shape memory, and duration of the process can be of orders of magnitude longer than hydrogen absorption. The dynamics of the out-of-equilibrium plastic creep are well described by the Avrami-type model of the nucleation and lateral domain wall expansion of the swelled sites.
\end{abstract}

Keywords: metal hydrides; hydrogen absorption; lattice response; palladium; palladium alloys

\section{Introduction}

An anticipated transition to hydrogen as the main ecologically clean mobile energy source [1,2] requires profound knowledge and understanding of the hydrogen-solid matter interactions for the treatment, storage and monitoring tasks. Hydrogen can penetrate reversibly a number of metals $(\mathrm{Pd}$, $\mathrm{Nb}, \mathrm{Ti}, \mathrm{Mg}, \mathrm{V}$, etc.), occupy the interstitial sites and cause a large expansion of the crystal lattice [3]. The question that remains surprisingly open after decades of research is whether the kinetics of hydrogen absorption and that of the structural response match each other. Coupling between the hydrogen migration and the lattice expansion is an important element in understanding the processes of hydrogenation and of the theoretical modelling of hydrogen diffusivity $[4,5]$. Despite an obvious importance of this assumption, there is little evidence on the time-dependent correlation between the two processes, mainly because of an experimental challenge to monitor each of them independently. Hydrogen atoms are invisible by the majority of lattice characterization tools, excluding neutron scattering [6,7]. On the other hand, the techniques used to study hydrogen diffusion [8] do not provide independent information on the structural evolution. In the absence of verification, the structural and strain time-dependent data are frequently taken as the information source on hydrogen diffusion, hydride phase transformations and their spatial distribution [9-11]. The assumption of the kinetics coupling is not obvious. Multiple out-of-equilibrium processes, where relaxation from a metastable state lags behind the state buildup, are known. Here, we demonstrate that such an out-of equilibrium process can occur in hydrogenated materials and that the kinetics of the structural response to the stress generated by hydrogen accommodation can differ significantly from that of hydrogen diffusion.

For the reasons clarified in the following, we studied two high-resistivity hydrogen-absorbing systems: (1) thin films of palladium, where resistivity is enhanced by surface scattering and fractal topology, and (2) CoPd alloys, where resistivity increases with Co concentration. Ferromagnetic CoPd alloys and multilayers attracted attention recently as materials for high-sensitivity magnetic detection of hydrogen using ferromagnetic resonance [12] and the extraordinary Hall effect [13,14]. 


\section{Experimental}

Experimental disentanglement between hydride formation and the lattice response has been achieved by a simple electric resistance measurement. Absorption of hydrogen increases the resistivity of bulk Pd [15-18] and Pd-rich alloys [19] by a value $\Delta \rho_{H}$ that depends on the concentration of the absorbed hydrogen and the composition and structure of the material. $\Delta \rho_{H}$ is few $\mu \Omega \mathrm{cm}$ in the $\mathrm{Pd}$ $\beta$-hydride state at room temperature [20]. Another contribution to the resistance change, overlooked in previous studies, is due to the expansion of thin films thickness. Thin films grown on rigid substrates cannot expand laterally within the film plane due to adhesion to the surface. Suppression of the in-plane expansion is equivalent to application of the in-plane compressive stress, leading to the out-of-plane expansion enhanced by Poisson's effect. The out-of-plane elastic expansion of the [111] textured Pd film is about $12.6 \%$ when the atomic ratio between $\mathrm{Pd}$ and the absorbed hydrogen is 1 [21]. The change in resistivity between the hydrogen-free state with resistance:

$$
R_{0}=\frac{\rho_{0}}{T_{0}} \cdot \frac{l}{w}
$$

and the hydrogenated state with:

$$
R_{1}=\frac{\rho_{1}}{T_{1}} \cdot \frac{l}{w}
$$

is:

$$
\Delta \rho=\frac{1}{1+\gamma}\left(\Delta \rho_{H}-\gamma \rho_{0}\right)
$$

where: $\rho_{0}$ is the initial resistivity, $T_{0}$ is the nominal thickness, and $l$ and $w$ are the length and width, respectively, of the film, that do not change during hydrogenation because of adhesion to the substrate. Thickness of the hydrogenated film is: $T_{1}=T_{0}+\Delta T=(1+\gamma) T_{0}$, where $\gamma=\Delta T / T_{0}$ is the thickness expansion coefficient (strain). For simplicity, we assume that resistivity follows Matthiessen's rule: $\rho_{1}=\rho_{0}+\Delta \rho_{H}$, and the initial $\rho_{0}$ is not affected by strain.

The geometrical (thickness expansion) term $\gamma \rho_{0}$ depends on the initial resistivity of the material. For thick Pd films with a resistivity of 10-15 $\mu \Omega \mathrm{cm}$, depending on the microstructure and the hydride term $\Delta \rho_{H} \approx 6 \mu \Omega \mathrm{cm}$ [20], the negative geometrical contribution is relatively small. However, in high resistivity films, where $\Delta \rho_{H} \ll \gamma \rho_{0}$, the geometrical term is dominant, the overall resistance response to hydrogen loading is negative, and $\Delta \rho \propto-\rho_{0}$. Reversal of the resistance response polarity from positive to negative at the critical resistivity threshold of about $50 \mu \Omega \mathrm{cm}$ in $4 \% \mathrm{H}_{2}$ atmosphere has been demonstrated in thin $\mathrm{Pd}$, thick $\mathrm{PdSiO}_{2}$ granular mixtures and $\mathrm{CoPd}$ alloy films with variable resistivity [22]. Earlier observations of the reduced resistance in the hydrogenated state were attributed to the lateral swelling of disconnected Pd clusters [23-27], contribution of hydrogen electrons to the conducting band [28], and even to the onset of room temperature superconductivity [29]. It seems, however, that inflation of a film thickness provides a simple and consistent explanation of the observed effects in both continuous and discontinuous hydrogenated films [22]. We adapt this interpretation and, in the following, distinguish between hydride formation and lattice expansion by the respectively positive and negative terms in the resistance response to hydrogen loading. The distinction among them is clear when the reversibility and the time dependence of the two processes are different.

The samples used in this study were $3 \mathrm{~nm}$ to $15 \mathrm{~nm}$ thick polycrystalline $\mathrm{Pd}$ and $\mathrm{Co}_{\mathrm{x}} \mathrm{Pd}_{100-\mathrm{x}}$ alloy films with lateral dimensions $5 \times 5 \mathrm{~mm}$ grown by the radio-frequency ( $\mathrm{rf}$ ) magnetron sputtering onto room-temperature glass substrates. Binary $\mathrm{Co}_{x} \mathrm{Pd}_{100-x}$ films with $\mathrm{Co}$ atomic concentrations in the range of $0 \leq x \leq 80$ were co-sputtered from separate targets (1.3" diameter and $2 \mathrm{~mm}$ thick). Co and Pd were soluble and form an equilibrium face-centered cubic (fcc) solid solution phase at all compositions during the room temperature deposition. No post-deposition annealing was done. The desired composition and thickness were controlled by the relative sputtering rates in the range of $0.01-0.1 \mathrm{~nm} / \mathrm{s}$ with the respective rf power between 0 and $85 \mathrm{~W}$ and tested by EDS (energy-dispersive X-ray spectroscopy) measurements. Resistance was measured using the Van der Pauw protocol. Electrical contacts were 
attached by bonding Al/Si wires. The setup was equipped with a gas-control chamber, which enabled performing measurements at variable hydrogen concentrations. The hydrogen-induced resistance changes were extracted from measurements performed in dry nitrogen and in $4 \% \mathrm{H}_{2} / \mathrm{N}_{2}$ mixture gas at $1 \mathrm{~atm}$ pressure at room temperature. The $15 \mathrm{~nm}$ thick and thinner $\mathrm{Pd}$ films were below the delamination thickness threshold [30] and were stable under repeated hydrogenation cycles. No buckling was observed in the CoPd samples at all tested thicknesses. The $15 \mathrm{~nm}$ thick films formed a continuous metallic layer. The $3 \mathrm{~nm}$ films had inhomogeneous meandric morphology with continuous metallic paths across the sample [22].

\section{Results and Discussion}

Figure 1 presents the resistivity response to a sequence of hydrogenation and dehydrogenation cycles (sequential exposure to $1 \mathrm{~atm} 4 \% \mathrm{H}_{2} / \mathrm{N}_{2}$ gaseous mixture followed by $\mathrm{N}_{2}$ ) of four $15 \mathrm{~nm}$ thick samples: pure $\mathrm{Pd}$ (a) and three $\mathrm{Co}_{x} \mathrm{Pd}_{100-x}$ alloys with $\mathrm{x}=15$ (b), $\mathrm{x}=30$ (c) and $\mathrm{x}=50$ (d). The starting resistivity in $\mathrm{N}_{2}$ is the lowest in Pd film $(22 \mu \Omega \mathrm{cm})$ and grows gradually in alloy samples with increasing Co content to $108 \mu \Omega \mathrm{cm}$ in $\mathrm{Co}_{50} \mathrm{Pd}_{50}$. The first exposure to hydrogen varies qualitatively with increasing Co content and initial resistivity; resistance increases sharply and saturates in the low resistivity Pd (a), increases sharply and decreases in (b), and decreases in samples (c) and (d) with higher resistivity $\left(\rho_{0}>50 \mu \Omega \mathrm{cm}\right.$ ). Removal of hydrogen is similar in all samples: resistance drops and saturates in $\mathrm{N}_{2}$. Starting from the second-third cycle the resistance response becomes reproducible and similar in all samples: resistance increases sharply when exposed to hydrogen and drops when hydrogen is removed (it will become clear in the following that reproducibility is achieved after a long-enough exposure to hydrogen and not due to the number of cycles). The final resistance in $\mathrm{N}_{2}$ is lower than the starting one in all samples. The entire sequence is a composition of reproducible rapid increase/decrease responses to the loading/unloading of hydrogen superposed with an irreversible gradual reduction in resistivity. Following the model above, the sequence can be interpreted as a superposition of reversible hydride formation-removal signals on the background of irreversible thickness inflation, while the relative magnitude and time duration of the latter increases with Co content. The overall resistance response of low resistivity Pd film (a) is dominated by the hydrogenation scattering contribution, while that of the high resistivity $\mathrm{Co}_{50} \mathrm{Pd}_{50}$ sample (d) by the irreversible thickness expansion.

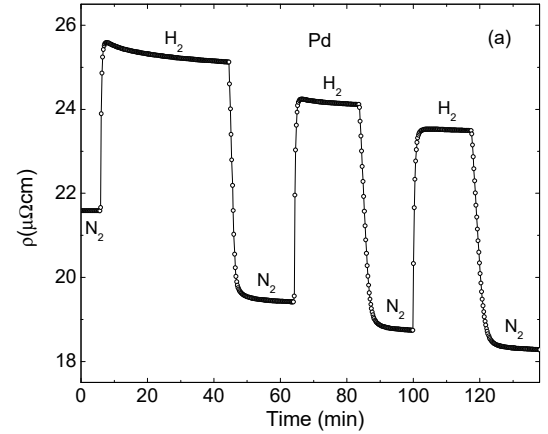

(a)

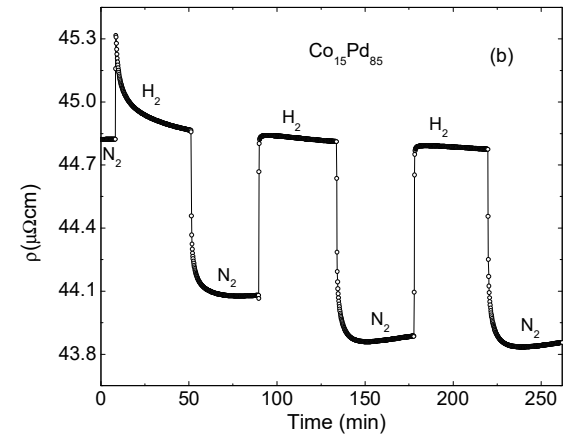

(b)

Figure 1. Cont. 


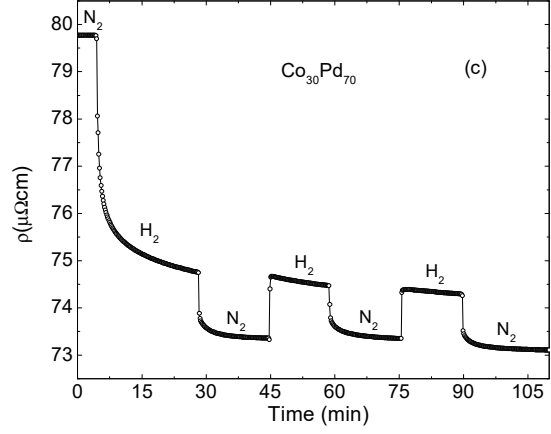

(c)

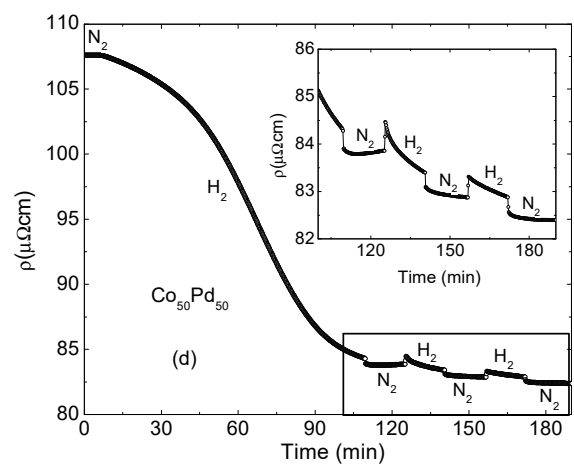

(d)

Figure 1. Resistivity response to a sequence of hydrogenation and dehydrogenation cycles (sequential exposure to a $1 \mathrm{~atm} 4 \% \mathrm{H}_{2} / \mathrm{N}_{2}$ gaseous mixture followed by $\mathrm{N}_{2}$ ) of four $15 \mathrm{~nm}$ thick samples: pure Pd (a) and three $\mathrm{Co}_{\mathrm{x}} \mathrm{Pd}_{100-\mathrm{x}}$ alloys with $\mathrm{x}=15(\mathbf{b}), \mathrm{x}=30$ (c) and $\mathrm{x}=50$ (d). The initial atmosphere is $\mathrm{N}_{2}$.

The difference in the kinetics of hydride formation and thickness inflation in pure Pd is demonstrated in Figure 2 for two identical $3 \mathrm{~nm}$ thick samples with a resistivity of $750 \mu \Omega \mathrm{cm}$ (this high resistivity is due to the vicinity to the conductance percolation threshold). The first sample was exposed continuously to hydrogen (solid line), while the second to a sequence of hydrogen loadings and removals (open circles). The immediate resistance increase in the hydrogen filling and drop in the respective removal (sample 2), interpreted as the hydride scattering term, indicate rapid hydrogen diffusion into and out of the metal. The sequence of the hydride terms is superposed with a slowly decreasing background. The irreversible reduction in resistance is equal in both samples; therefore, the final thickness expansions are identical. Two points are notable: (1) the lattice response is much slower than the hydrogen diffusion in and out of the material; (2) the lattice expansion is frozen when hydrogen is extracted (resistance is constant in $\mathrm{N}_{2}$ ), and the process of expansion is recovered from the same state when the hydride is recovered (resistance increases on reloading to the same value prior to hydrogen extraction. See Figure 2). Thus, the system demonstrates the shape memory. It is worth noting that partial thickness recovery is observed when films are flushed in air instead of nitrogen.

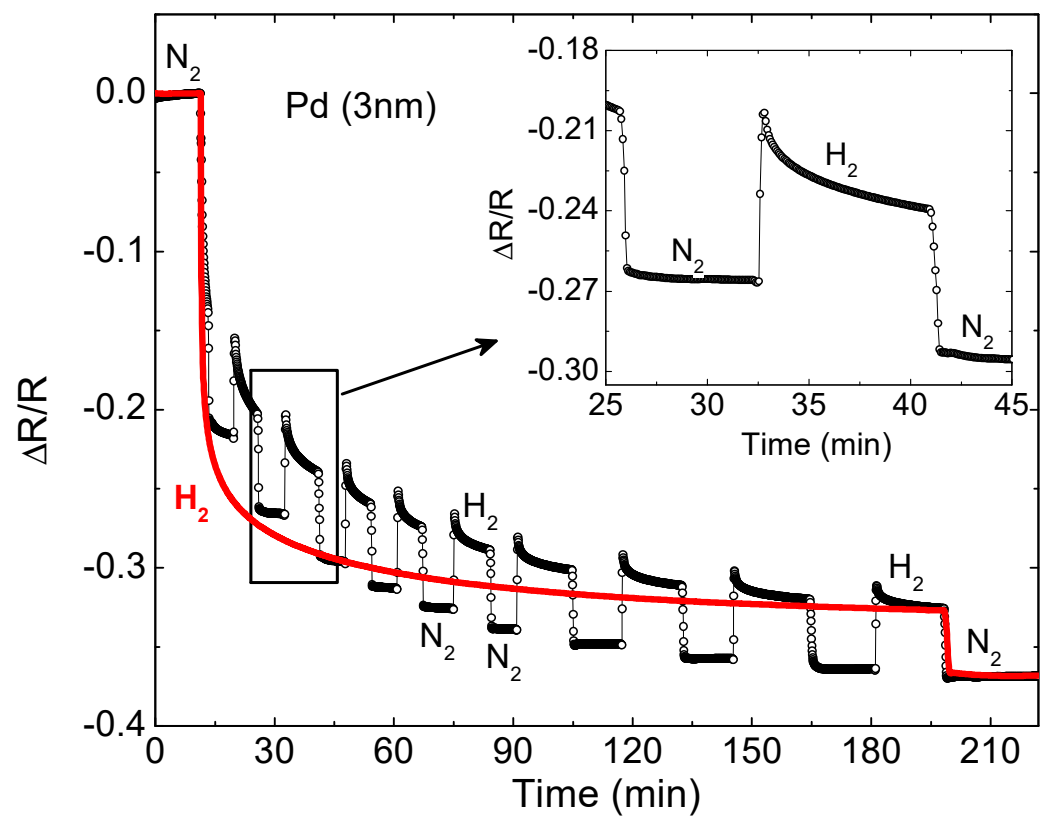

Figure 2. Time-dependent normalized resistance of $3 \mathrm{~nm}$ thick Pd exposed continuously to a $4 \% \mathrm{H}_{2} / \mathrm{N}_{2}$ mixture (solid red line) and to a sequence of hydrogenation and dehydrogenation cycles (open circles). Inset: zoom on one of the $\mathrm{H}_{2}-\mathrm{N}_{2}$ cycles. Resistance is frozen in $\mathrm{N}_{2}$ and decreases in $\mathrm{H}_{2}$. 
The time dependence of the normalized resistance changes due to hydride formation $\frac{\Delta R_{H}}{\Delta R_{H, \max }}$ and thickness expansion $\frac{\Delta R_{T}}{\Delta R_{T, \max }}$ are shown in Figure 3a,b, respectively, for a number of $15 \mathrm{~nm}$ thick CoPd films with different Co concentrations, including a pure Pd film. $\Delta R_{H(T), \text { max }}$ are the largest saturated values of the respective changes for each sample. Figure $3 c$ presents the effective time of each process $t_{H, 50}$ and $t_{T, 50}$ defined as the time at which the respective resistance term changed by half. Hydride formation is accomplished within a few tens to hundred seconds in all samples. In alloys, the process of hydride formation is quicker with increasing Co content: $t_{50}=60 \mathrm{~s}$ in $\mathrm{Co}_{10} \mathrm{Pd}_{90}$ down to a few $\mathrm{s}$ in $\mathrm{Co}_{40} \mathrm{Pd}_{60}$. The increase in the diffusion rate in diluted $\mathrm{Pd}$ alloys is consistent with that reported for NiPd alloys [31]. The thickness expansion time scale is entirely different: from $10 \mathrm{~s}$ in the $\mathrm{x}=20$ sample to $10^{5} \mathrm{~s}$ in the $\mathrm{x}=80$ one. $t_{T, 50}$ can be approximated by: $t_{T, 50} \propto e^{x}$ (solid line in Figure $3 \mathrm{c}$ ), i.e., it increases exponentially with the concentration of Co.

The shape of the time-dependent $\Delta R_{T}(t)$ (Figure 3b) is informative. At low Co content, $\Delta R_{T}$ drops immediately with exposure to hydrogen. The creep rate $d R_{T} / d t$ is intuitively clear: it is at its maximum at the beginning when stress is the highest, and decreases with time when stress is released gradually by plastic deformations. Co-rich samples demonstrate a different behavior: an onset of expansion occurs after a long delay and the relaxation curve has a characteristic S-shape (see Figure 1d in a linear time scale). Such dynamics can be understood in the framework of the Avrami or the Johnson-Mehl-Avrami-Kolmogorov (JMAK) model [32-37], which was first formulated to describe kinetics of isothermal recrystallization of metals. The transformation proceeds by nucleation and growth of a new phase, and can be summed up by a simple formula: $V(t)=1-e^{-V_{e}(t)}$, where $\mathrm{V}$ is the fraction of the transformed phase and $V_{e}$ is the so-called extended volume of the transformed phase, that is, the volume the transformed phase would acquire if the overlap among the growing nuclei was disregarded. In general, the model can describe any non-coherent transition from a metastable state to the lowest energy equilibrium state by a sequence of local transition events occurring when energy barriers prevent an immediate global transition to the equilibrium. The phenomenology appeared to be quite universal and the model was used, among others, in describing the kinetics of thin film growth [38], phase transition in ferroelectrics [39,40], magnetization reversal in ferromagnets [41-43], distribution of infections in networks [44] and evolution of religions [45]. In ferromagnets, it was used to describe the reversal of magnetization in the magnetized films subjected to an external magnetic field antiparallel to the magnetization vector. The equilibrium state is the one in which the magnetization is oriented parallel to the applied field, and the metastable one is when the magnetization and field are antiparallel. If the field value is smaller than required to overcome the magnetic anisotropy energy barrier, the magnetization reverses not by a coherent rotation in the entire volume but rather by a sequence of distributed non-coherent local events. The Fatuzzo-Labrune theory $[39,41]$ describes the process by two microscopic phenomena: nucleation of new domains with reversed magnetization, and their expansion by domain wall propagation. In the case of the hydrogenated films, the metastable state can be created when hydrogen atoms diffuse into the material, occupy the interstitial states, and generate an internal pressure on the lattice, while an immediate expansion is prevented by either the thermodynamic constrains, such as the phase transition between the $\alpha$ and $\beta$ states, or/and by the structural ones, such as adhesion to a substrate. In analogy with the Fatuzzo-Labrune theory $[39,41]$, we model the process of thickness deformation by nucleation of new "swelled" domains and their lateral expansion due to domain wall propagation. These are described by the probability of nucleation per unit time $p_{n}$ and by the effective domain wall velocity $v$. The entire process can be characterized by a dimensionless parameter $k$ defined as:

$$
k=\frac{v}{p_{n} r_{n}}
$$


in which $r_{n}$ is the radius of a nucleation site. Temporal variation of resistance is analytically simple in two limiting cases: one in which the nucleation rate dominates and $k \ll 1$, and another in which the domain wall propagation is dominant and $k \gg 1$ :

$$
\frac{\Delta R_{T}}{\Delta R_{T, \max }}=\left\{\begin{array}{ll}
\exp \left[-\frac{k^{-2}\left(p_{n} t\right)^{3}}{3}\right]-1, & k \gg 1 \\
\exp \left(-p_{n} t\right)-1, & k \ll 1
\end{array}\right\}
$$

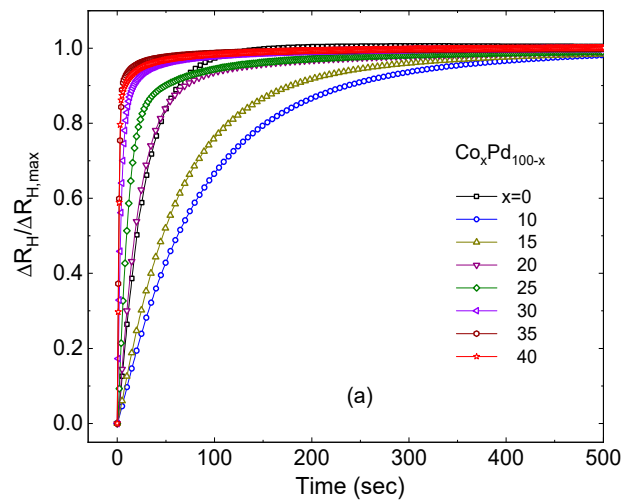

(a)

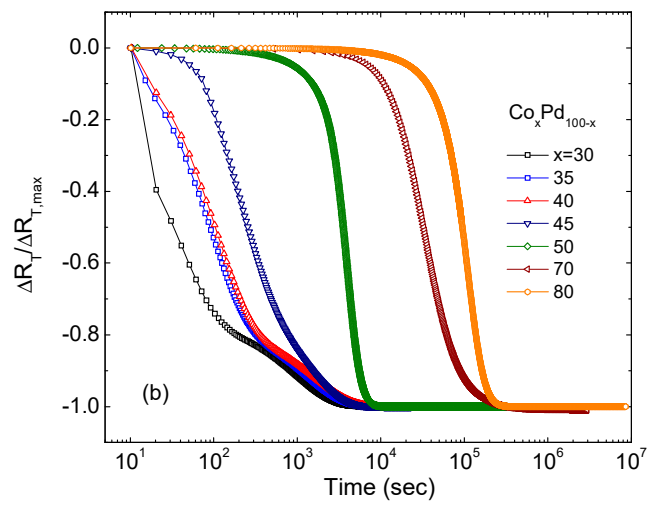

(b)

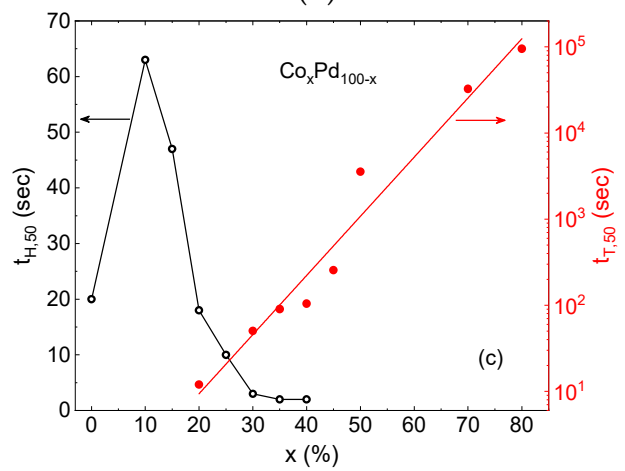

(c)

Figure 3. Time dependence of the normalized resistance changes due to hydride formation $\frac{\Delta R_{H}}{\Delta R_{H}, \max }$ (a) and thickness expansion $\frac{\Delta R_{T}}{\Delta R_{T, m a x}}(\mathbf{b})$ of $15 \mathrm{~nm}$ thick $\mathrm{Co}_{\mathrm{x}} \mathrm{Pd}_{100-\mathrm{x}}$ alloys with different $\mathrm{Co}$ content $\mathrm{x}$. (c) The half-time of hydride formation $t_{H, 50}$ (left vertical axis) and of thickness expansion $t_{T, 50}$ (right vertical axis) as a function of Co concentration $x$. Lines are guides for the eye. 
The Fatuzzo-Labrune model does not account for the final stage of the process when the last stressed regions are annihilated. This final stage can be fitted by an additional exponential term $\exp \left(-p_{a} t\right)$ where $p_{a}$ is the site annihilation probability [42,43]. Dimensions of the nucleation and annihilation sites are assumed to be similar. The entire creep process in terms of the varying effective thickness $\Delta T(t)$ is given by:

$$
\begin{gathered}
\frac{\Delta T(t)}{\Delta T_{\max }}=1-\frac{\Delta R_{T}(t)}{\Delta R_{T, \text { max }}}=\left\{\begin{array}{cc}
1-\left\{\operatorname{Aexp}\left[-\frac{k^{-2}\left(t / \tau_{n}\right)^{3}}{3}\right]+B \exp \left(-t / \tau_{a}\right)\right\}, & k \gg 1 \\
1-\left[A \exp \left(-t / \tau_{n}\right)+B \exp \left(-t / \tau_{a}\right)\right], & k \ll 1
\end{array}\right\} \\
\text { with } A+B=1,
\end{gathered}
$$

where $\tau_{n}=1 / p_{n}$ and $\tau_{a}=1 / p_{a}$ are the effective relaxation and annihilation time, respectively.

Figure 4 presents a convincing fitting of Equation (6) (solid lines) to the time-dependent data (symbols) for the $3 \mathrm{~nm}$ thick Pd film (a) and two $15 \mathrm{~nm}$ alloy samples: $\mathrm{Co}_{35} \mathrm{Pd}_{65}$ (b) and $\mathrm{Co}_{70} \mathrm{Pd}_{30}(\mathrm{c})$. The first two are well fitted in the $k \ll 1$ limit $\left(\mathrm{Pd}: \tau_{n}=5 \times 10^{2} \mathrm{~s}\right.$ and $\tau_{a}=8 \times 10^{3} \mathrm{~s} ; \mathrm{Co}_{35} \mathrm{Pd}_{65}: \tau_{n}=1 \times$ $10^{2} \mathrm{~s}$ and $\left.\tau_{a}=1 \times 10^{3} \mathrm{~s}\right)$, while $\mathrm{Co}_{70} \mathrm{Pd}_{30}$ fits the $k \gg 1$ one $\left(k=95, \tau_{n}=6 \times 10^{4} \mathrm{~s}\right.$ and $\left.\tau_{a}=1 \times 10^{5} \mathrm{~s}\right)$, in which the nucleation is rare and the incubation time is long compared with lateral expansion of the nucleated domains.

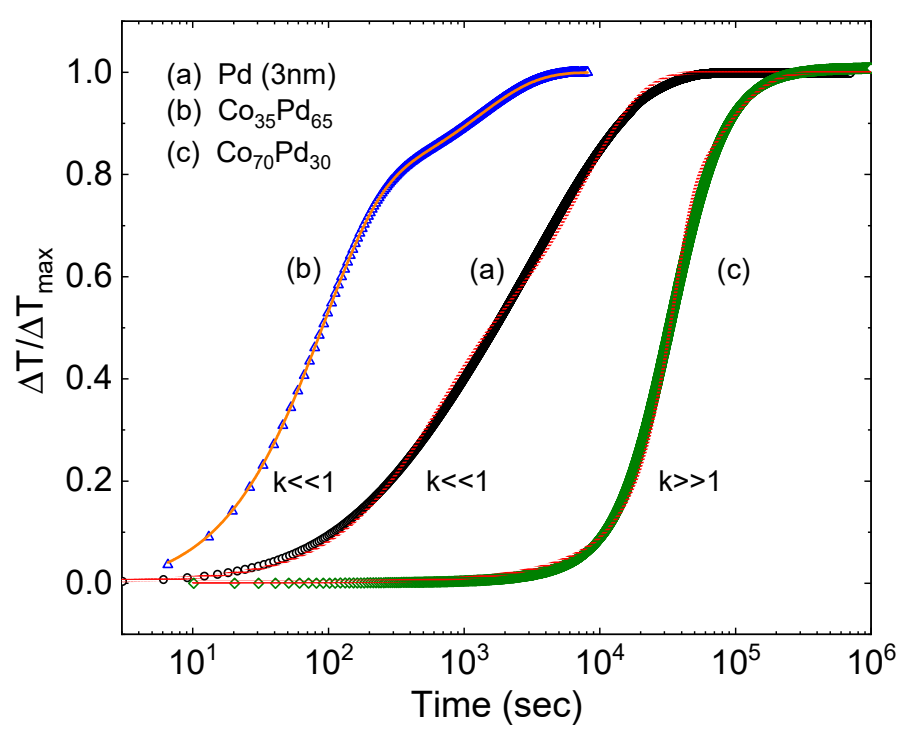

Figure 4. Normalized change of thickness as a function of the hydrogen exposure time of $3 \mathrm{~nm}$ thick $\mathrm{Pd}$ (a), $15 \mathrm{~nm}$ thick $\mathrm{Co}_{35} \mathrm{Pd}_{65}$ (b) and $15 \mathrm{~nm}$ thick $\mathrm{Co}_{70} \mathrm{Pd}_{30}$ (c) films. Symbols represent the experimental data and lines are fitted by Equation (3). Samples (a) and (b) were fitted in the $k \ll 1$ limit and sample (c) in the $k \gg 1$ one.

The conclusions of this work are based on a given interpretation of the resistance data. Credibility of the interpretation is supported by the results obtained by other techniques reported in the literature. Irreversible changes in the crystalline structure and evidence of plastic out-of-plane expansion in thin Pd films during the $\beta$-phase formation were found by XRD [21,46,47] and microcantilever [48] measurements. Similar irreversible expansion of thickness was also observed in other hydrogenated metals: Nb films [49], Mg-Y, Mg-Ni [50] and PdAg [51] alloys. Exponential time-dependent thickness swelling was found in $\mathrm{Nb}$ films exposed to hydrogen by the scanning tunneling microscopy (STM) measurements, while the time scale exceeded by far the values expected for the hydrogen diffusion time [49]. The divergence of the plastic deformation time in Co-rich samples is consistent with the superior creep stability of fcc Co-based superalloys [52]. 
To summarize, the kinetics of hydrogen penetration into metals can differ significantly from the respective lattice response. Hydrogenation of $\mathrm{Pd}$ and $\mathrm{CoPd}$ films in $4 \% \mathrm{H}_{2} / \mathrm{N}_{2}$ atmosphere creates an out-of-equilibrium state in which stress is built up rapidly with hydrogen absorption and is released by a slow plastic thickness growth. Expansion of thickness is irreversible. The creep can be frozen by removal of hydrogen and restarted from the frozen state by hydrogen reloading. Thus, the material demonstrates the shape memory. The dynamics of the creep can be described by the Avrami-type model with the nucleation of isolated swelled sites and lateral domain wall expansion. The nucleation rate slows down in Co-rich alloys, such that an effective thickness inflation can occur $30 \mathrm{~h}$ after the exposure to hydrogen and five orders of magnitude slower than the gas diffusion time.

Author Contributions: Investigation was done by S.S.D. and G.K.; A.G. supervised and wrote the original draft. All authors have read and agreed to the published version of the manuscript.

Funding: The work was supported by the Israel Science Foundation grant No. 992/17.

Conflicts of Interest: The authors declare no conflict of interest.

\section{References}

1. European Commission. Communication from the Commission to the European Parliament, the Council, the European Economic and Social Committee and the Committee of the Regions. A Hydrogen Strategy for a Climate-Neutral Europe, (European Commission; Brussels, 8.7.2020). Available online: https://ec.europa.eu/ energy/sites/ener/files/hydrogen_strategy.pdf (accessed on 30 July 2020).

2. Gielen, D.; Taibi, E.; Miranda, R. Hydrogen: A Renewable Energy Perspective; International Renewable Energy Agency (IRENA): Abu Dhabi, UAE, 2019; ISBN 978-92-9260-151-5.

3. Fukai, Y. The Metal-Hydrogen System: Basic Bulk Properties; Springer Series in Materials Science; Springer-Verlag: Berlin/Heidelberg, Germany, 2005; Volume 21.

4. Gillan, M.J. Quantum simulation of hydrogen in metals. Phys. Rev. Lett. 1987, 58, 563. [CrossRef] [PubMed]

5. Kimizuka, H.; Ogata, S.; Shiga, M. Mechanism of fast lattice diffusion of hydrogen in palladium: Interplay of quantum fluctuations and lattice strain. Phys. Rev. B 2018, 97, 014102. [CrossRef]

6. Callori, S.J.; Rehm, C.; Causer, G.L.; Kostylev, M.; Klose, F. Hydrogen absorption in metal thin films and heterostructures investigated in situ with neutron and X-ray scattering. Metals 2016, 6, 125. [CrossRef]

7. Kofu, M.; Yamamuro, O. Dynamics of atomic hydrogen in palladium probed by neutron spectroscopy. $J$. Phys. Soc. Jpn. 2020, 89, 051002. [CrossRef]

8. Wipf, H. (Ed.) Hydrogen in Metals III: Properties and Applications; Springer: Berlin/Heidelberg, Germany, 1997; p. 51.

9. Delmelle, R.; Proost, J. An in situ study of the hydriding kinetics of Pd thin films. Phys. Chem. Chem. Phys. 2011, 13, 11412-11421. [CrossRef]

10. Delmelle, R.; Amin-Ahmadi, B.; Sinnaeve, M.; Idrissi, H.; Pardoen, T.; Schryvers, D.; Proost, J. Effect of structural defects on the hydriding kinetics of nanocrystalline Pd thin films. Int. J. Hydrog. Energy 2015, 40, 7335. [CrossRef]

11. Ulvestad, A.; Welland, M.J.; Collins, S.S.E.; Harder, R.; Maxey, E.; Wingert, J.; Singer, A.; Hy, S.; Mulvaney, P.; Zapol, P.; et al. Avalanching strain dynamics during the hydriding phase transformation in individual palladium nanoparticles. Nat. Commun. 2015, 6, 10092. [CrossRef]

12. Chang, S.; Kostylev, M.; Ivanov, E. Metallic spintronic thin film as a hydrogen sensor. Appl. Phys. Lett. 2013, 102, 142405. [CrossRef]

13. Gerber, A.; Kopnov, G.; Karpovski, M. Hall effect spintronics for gas detection. Appl. Phys. Lett. 2017, 111, 143505. [CrossRef]

14. Das, S.S.; Kopnov, G.; Gerber, A.J. Detection of hydrogen by the extraordinary Hall effect in CoPd alloys. Appl. Phys. 2018, 124, 104502. [CrossRef]

15. Flanagan, T.B.; Lewis, F.A. Hydrogen absorption by palladium in aqueous solution. Trans. Faraday Soc. 1959, 55, 1400. [CrossRef]

16. Fletcher, R.; Ho, N.S.; Manchester, F.D. The residual resistivity and low temperature thermopower of palladium hydrogen alloys. J. Phys. C Solid State Phys. 1970, 3, S59. [CrossRef] 
17. Sakamoto, Y.; Takai, K.; Takashima, I.; Imada, M. Electrical resistance measurements as a function of composition of palladium-hydrogen (deuterium) systems by a gas phase method. J. Phys. Condens. Matter 1996, 8, 3399. [CrossRef]

18. Geerken, B.M.; Griessen, R. Concentration and temperature dependence of the electrical resistivity of quenched PdHx. J. Phys. F: Met. Phys. 1983, 13, 963. [CrossRef]

19. Baba, K.; Miyagawa, U.; Watanabe, K.; Sakamoto, Y.; Flanagan, T.B. Electrical resistivity changes due to interstitial hydrogen in palladium-rich substitutional alloys. J. Mater. Sci. 1990, 25, 3910. [CrossRef]

20. Wagner, S.; Pundt, A. Electrical resistivity and hydrogen solubility of PdHc thin films. Acta Mater. 2010, 58, 1387-1394. [CrossRef]

21. Wagner, S.; Kramer, T.; Uchida, H.; Dobron, P.; Cizek, J.; Pundt, A. Mechanical stress and stress release channels in 10-350 nm palladium hydrogen thin films with different micro-structures. Acta Mater. 2016, 114, 116-125. [CrossRef]

22. Das, S.S.; Kopnov, G.; Gerber, A. Positive vs negative resistance response to hydrogenation in palladium and its alloys. AIP Adv. 2020, 10, 065129. [CrossRef]

23. Wu, F.; Morris, J.E. The effects of hydrogen absorption on the electrical conduction in discontinuous palladium films. Thin Solid Films 1994, 246, 17-23.

24. Barr, A. The effect of hydrogen absorption on the electrical conduction in discontinuous palladium films. Thin Solid Films 1977, 41, 217-226. [CrossRef]

25. Xu, T.; Zach, M.P.; Xiao, Z.L.; Rosenmann, D.; Welp, U.; Kwok, W.K.; Crabtree, G.W. Self-assembled monolayer-enhanced hydrogen sensing with ultrathin palladium films. Appl. Phys. Lett. 2005, 86, 203104. [CrossRef]

26. van Lith, J.; Lassesson, A.; Brown, S.A.; Schulze, M.; Partridge, J.G.; Ayesh, A. A hydrogen sensor based on tunneling between palladium clusters. Appl. Phys. Lett. 2007, 91, 181910. [CrossRef]

27. Kajita, S.; Hasebe, Y.; Fukunaga, T.; Matsubara, E. Abnormal behavior of hydrogen response and hydrogen induced linear expansion coefficient of Pd-Cu-Si metallic glassy alloys for thin film hydrogen sensor. Mater. Trans. 2011, 52, 1148-1156. [CrossRef]

28. Spasojević, M.; Maričić, A.; Zelenović, L.R.; Krstajić, N.; Spasojević, P. The kinetics of hydrogen absorption/desorption within nanostructured composite Ni79. 1Co18. 6Cu2. 3 alloy using resistometry. J. Alloys Compd. 2013, 551, 660-666. [CrossRef]

29. Tripodi, P.; Di Gioacchino, D.; Vinko, J.D. Superconductivity in PdH: Phenomenological explanation. Physica C Supercond. 2004, 410, 350-352. [CrossRef]

30. Lee, E.; Lee, J.M.; Koo, J.H.; Lee, W.; Lee, T. Hysteresis behavior of electrical resistance in Pd thin films during the process of absorption and desorption of hydrogen gas. Int. J. Hydrog. Energy 2010, 35, 6984-6991. [CrossRef]

31. Lee, E.; Lee, J.M.; Lee, E.; Noh, J.S.; Joe, J.H.; Jung, B.; Lee, W. Hydrogen gas sensing performance of Pd-Ni alloy thin films. Thin Solid Films 2010, 519, 880-884. [CrossRef]

32. Kolmogorov, A.N. On the statistical theory of the crystallization of metals. Bull. Acad. Sci. URSS 1937, 3, 355.

33. Avrami, M. Kinetics of phase change. I general theory. J. Chem. Phys. 1939, 7, 1103. [CrossRef]

34. Avrami, M. Kinetics of phase change. II transformation-time relations for random distribution of nuclei. J. Chem. Phys. 1940, 8, 212. [CrossRef]

35. Avrami, M. Granulation, phase change, and microstructure kinetics of phase change. III. J. Chem. Phys. 1941, 9, 177. [CrossRef]

36. Johnson, W.A. Reaction kinetics in processes of nucleation and growth. Am. Inst. Min. Metal. Petro. Eng. 1939, 135, 416-458.

37. Mehl, R.F.; Cahn, R.W. Physical Metallurgy; Cahn, R.W., Haasen, P., Eds.; North-Holland Physics Publishing: Oxford, UK, 1983.

38. Fanfoni, M.; Tomellini, M. The Johnson-Mehl-Avrami-Kohnogorov model: A brief review. Il Nuovo Cimento D 1998, 20, 1171-1182. [CrossRef]

39. Fatuzzo, E. Theoretical considerations on the switching transient in ferroelectrics. Phys. Rev. 1962, 127, 1999. [CrossRef]

40. Orihara, H.; Hashimoto, S.; Ishibashi, Y. A theory of DE hysteresis loop based on the Avrami model. J. Phys. Soc. Jpn. 1994, 63, 1031-1035. [CrossRef] 
41. Labrune, M.; Andrieu, S.; Rio, F.; Bernstein, P. Time dependence of the magnetization process of RE-TM alloys. J. Magn. Magn. Mater. 1989, 80, 211-218. [CrossRef]

42. Windsor, Y.W.; Gerber, A.; Karpovski, M. Dynamics of successive minor hysteresis loops. Phys. Rev. B 2012, 85, 064409. [CrossRef]

43. Windsor, Y.W.; Gerber, A.; Korenblit, I.Y.; Karpovski, M. Time dependence of magnetization reversal when beginning with pre-existing nucleation sites. J. Appl. Phys. 2013, 113, 223902. [CrossRef]

44. Avramov, I. Kinetics of distribution of infections in networks. Phys. A Stat. Mech. Appl. 2007, 379, 615-620. [CrossRef]

45. Ausloos, M.; Petroni, F. Statistical dynamics of religion evolutions. Phys. A Stat. Mech. Appl. 2009, 388, 4438-4444. [CrossRef]

46. Harumoto, T.; Ohnishi, Y.; Nishio, K.; Ishiguro, T.; Shi, J.; Nakamura, Y. In-situ X-ray diffraction study of hydrogen absorption and desorption processes in Pd thin films: Hydrogen composition dependent anisotropic expansion and its quantitative description. AIP Adv. 2017, 7, 065108. [CrossRef]

47. Kawasaki, S.; Itoh, K.; Shima, K.; Kato, H.; Ohashi, T.; Ishikawa, T. Yamazaki. Change in the crystalline structure during the phase transition of the palladium-hydrogen system. Phys. Chem. Chem. Phys. 2015, 17, 24783-24790. [CrossRef] [PubMed]

48. Ollagnier, A.; Fabre, A.; Thundat, T.; Finot, E. Activation process of reversible Pd thin film hydrogen sensors. Sens. Actuators B Chem. 2013, 186, 258-262. [CrossRef]

49. Nörthemann, R.; Kirchheim, A.; Pundt, J. Surface modification of Nb-films during hydrogen loading. Alloys Compd. 2003, 357, 541-544. [CrossRef]

50. Yamada, Y.; Miura, M.; Tajima, K.; Okada, M.; Yoshimura, K. Film thickness change of switchable mirrors using Mg-Y alloy thin films due to hydrogenation and dehydrogenation. Sol. Energy Mater. Sol. Cells 2014, 126, 237. [CrossRef]

51. Jovanović, Z.; De Francesco, M.; Tosti, S.; Pozio, A. Structural modification of PdAg alloy induced by electrolytic hydrogen absorption. Int. J. Hydrog. Energy 2011, 36, 7728. [CrossRef]

52. Donachie, M.J.; Donachie, S.J. Superalloys: A Technical Guide; ASM International: Materials Park, OH, USA, 2002; ISBN 0-87170-749-7.

Sample Availability: Samples of the compounds are not available from the authors.

(C) 2020 by the authors. Licensee MDPI, Basel, Switzerland. This article is an open access article distributed under the terms and conditions of the Creative Commons Attribution (CC BY) license (http://creativecommons.org/licenses/by/4.0/). 